\title{
Editorial
}

doi:10.1038/sj.sc.3101313

\section{Treatment of spasticity}

The clinical syndrome of spastic paresis usually develops some weeks after an acute central nervous system lesion. It is characterized by increased muscle tone and exaggerated tendon reflexes. Several electrophysiological methods were used to examine the basic segmental pathophysiological mechanisms of spasticity. It was found that with different frequencies alphamotoneurone-activity, gamma motoneurone activity and common interneurone activity were increased, whereas presynaptic inhibition of spindle Ia afferents was reduced. ${ }^{1}$ But the interindividual correlation between the electrophysiological measures and the clinical syndrome of spasticity at least when under medication was low. For example, a reanalysis of the data from studies on the effect of physical therapy revealed that about half of the spastic patients under medication had normal F-wave-amplitudes but increased muscle tone. ${ }^{2}$ New data show that the movement disorder associated with spastic pareses is mainly due to secondary changes of muscle properties which require a specific treatment. ${ }^{3}$ So the contribution of central nervous pathophysiological changes to the syndrome of spasticity may be lower than expected. There may be a difference between hemiplegics and paraplegics, because in paraplegics the reduction of presynaptic inhibition is more pronounced than in hemiplegics. ${ }^{3}$ But in patients with spasticity in the course of multiple sclerosis there was a close relationship between an electrophysiological measure of spasticity, which was not dependent on any muscle responses, and increased muscle tone. ${ }^{2}$ Therefore, central nervous effects on spasticity should not be neglected. A comprehensive treatment of spasticity should take into account the segmental pathophysiological changes in spinal cord as well as the changes in muscle properties.

The surgical treatment may be traced back to Otfrid Foerster, who conceptualized posterior rhizotomy as a cure for spasticity in the first decade of the last century. ${ }^{4}$ This procedure is still regarded as a potential treatment especially in children. ${ }^{5}$ Another method of treating spasticity by inducing new lesions is the intrathecal use of neurolytic agents like phenol and alcohol. ${ }^{6}$ But in the last three decades of the last century non-lesional techniques such as pharmacotherapy and physiotherapy became predominant in the treatment of spasticity. Benzodiazepines and tizanidine decrease motoneuron activity and reinforce presynaptic inhibition, which is mediated by gamma-aminobutyric acid.7 Another GABAergic drug, baclofen, normalizes the altered common interneuron activity and decreases motoneuron activity as well. ${ }^{8}$ Additionally the common interneuron activity may be influenced by NMDA-antagonists like memantine, flupirtine and gabapentin. ${ }^{9}$ Botulinum toxin A given intramuscularly results in a temporary chemodenervation and the loss or reduction of neuronal activity at the target muscle. This includes gamma motoneurone activity and leads by its reduction to a decrease of Ia spindle afferent activity. As a consequence alphamotoneuron activity is reduced even in non-treated muscles. ${ }^{10}$ There are hints that surgical interventions intended to improve the ability to walk and stand are made possible and facilitated by treatment with botulinum toxin. Results are best when botulinum toxin is combined with physiotherapy and oral antispastic medication. ${ }^{11}$ Physiotherapy may reduce alpha-motoneuron activity ${ }^{12}$ even when it is reduced to a thirty-minute training with a motorized exercisecycle. ${ }^{13}$ Physiotherapy is especially useful to reactivate residual motoric functions and prevent the development of myogenic contracture. It is therefore the core element of a comprehensive treatment for the syndrome of spasticity. ${ }^{3}$ For future treatment options there are many experimental studies on animals, especially on rats, which try to support neuronal plasticity and regeneration in spinal cord. Growth inhibiting substances may be eliminated by specific antibodies given intrathecally and embryonal nerval tissue or gliacytes from the N. olfactorius may support the restitution of descending projections even in spinal cord lesions. ${ }^{14}$

\section{J Rösche \\ Die Weissenau, Department of Neurology and Epileptology (Department of Psychiatry I, University of Ulm) Weingartshoferstrasse 2, D-88214 Ravensburg-Weissenau Germany}

\section{References}

1 Milanov I. Examination of segmental pathophysiological mechanisms of spasticity. Electromyogr Clin Neurophysiol 1994; 34: 73 - 79.

2 Rösche J, Mauch E. Increased V/D-ratio in lumbosacral SEP's as a new electrophysiological measure of spasticity. Spinal Cord 2000; 38: 287-291.

3 Dietz V. Syndrom der spastischen Parese. Akt Neurol 2001; 28: $49-52$. 
4 Foerster O. Über eine neue operative Methode der Behandlung spastischer Lähmungen mittels Resektion hinterer Rückenmarkswurzeln. Z orthop Chir 1908; 22: $203-223$.

5 McLaughlin $\mathbf{J}$ et al. Selective dorsal rhizotomy: metaanalysis of three randomised controlled trials. Dev Med Child Neurol 2002; 44: 17-25.

6 Zafonte RD, Munin MC. Phenol and alcohol blocks for the treatment of spasticity. Phys Med Rehabil Clin N Am 2001; 12: $817-832$.

7 Delwaide PJ. Electrophysiological analysis of the mode of action of muscle relaxants in spasticity. Ann Neurol 1985; 17: $90-95$.

8 Milanov IG. Mechanisms of baclofen action on spasticity. Acta Neurol Scand 1992; 85: 305-310.

9 Block F, Kosinski CM. Glutamatantogonisten in der Neurologie. Nervenarzt 2001; 72: 393 - 405.
10 Wohlfahrt K et al. Remote F-wave changes after local botulinum toxin application. Clin Neurophysiol 2001; 112: $636-640$

11 Reichel G. Botulinum toxin for treatment of spasticity in adults. J Neurol 2001; 248 (Suppl 1): I/25-I/27.

12 Rösche $\mathrm{J}$ et al. Effects of physiotherapy on F-waveamplitudes in spasticity. Electromyogr Clin Neurophysiol 1996; 36: $509-511$

13 Rösche $\mathrm{J}$ et al. The effects of therapy on spasticity utilizing a motorized exercise-cycle. Spinal Cord 1997; 35: $176-178$

14 Schmitt AB et al. Mechanismen der Nervenregeneration im ZNS - Fortschritte in der experimentellen Parapleologie. Akt Neurol 2001; 28: 161 - 169. 